\title{
Adapting craniosacral therapy to treat horses
}

\author{
Weronika Kanik $^{1}$, Jacek Augustyn ${ }^{2 \dagger}$, Barbara Tombarkiewicz ${ }^{1}$ \\ ${ }^{1}$ University of Agriculture in Krakow, Faculty of Animal Breeding and Biology, Department of Veterinary, \\ Reproduction and Welfare of Animals, Institute of Veterinary Sciences, Krakow, Poland \\ ${ }^{2} \mathrm{AGH}$ University of Science and Technology, Faculty of Electrical Engineering, Automatics, \\ Computer Science and Biomedical Engineering, Krakow, Poland
}

Received January 24, 2016

Accepted February 17, 2017

\begin{abstract}
Craniosacral therapy is an acknowledged therapeutic method used for treating humans. It derives from osteopathy, being a manual technique which uses a very gentle touch. It consists in balancing the fluctuation of cerebrospinal fluid by applying appropriate holds that make it possible for the patient's organism to release tensions which have formed in tissues. The aim of the present work was to depict the possibility to adapt the method of craniosacral therapy used in humans to the therapy of horses. Thirteen therapeutic holds proposed for the treatment of horses were described and interpreted graphically on the basis of therapy of 62 horses with different disorders. A total of 241 craniosacral therapy treatments were performed. The adaptation of presented craniosacral therapy holds to equine therapy was developed by the first author on the basis of relevant holds used in the biodynamic craniosacral therapy in humans and in own therapeutic practice. The effects of own practice and data available in literature suggest that craniosacral therapy seems to be an effective method of improving the state of health of horses suffering from different complaints that may cause major difficulties in sport, breeding or private use of the animals. The use of thermography made it possible to record the effects of therapy and some processes accompanying it, which had been impossible before.
\end{abstract}

Equine, rehabilitation, convalescence, cerebrospinal fluid, thermography

When different complaints in humans such as migraine, chronic pain, arthritis, sciatica, pain in the spine, myalgia, post-traumatic symptoms and many others that constitute a serious impediment in everyday life are treated, in many cases the treatment lasts several years without any improvement and the prognosis is poor. These disorders have different causes, however, many of them can be attributed to a disturbance in the fluctuation of the cerebrospinal fluid. Balancing and restoring the correct fluctuation of the fluid is possible, among others, thanks to craniosacral therapy (CST) (Sutherland 1990, 1998; Sills 2001, 2004, 2011, 2013; Whedon and Glassey 2009; Kern 2010). Craniosacral therapy is rooted in osteopathy (Sutherland 1939; Upledger and Vredevoogd 1983; Upledger 1997; Sills 2001; Kern 2010). It is a manual approach in which a very gentle type of touch is used, the so-called butterfly touch. It consists in balancing the fluctuation of the cerebrospinal fluid by applying certain holds that make it possible for the organism of the patient to release tensions which have accumulated in tissues. This method was developed in the 1920s by William G. Sutherland, D.O. (Sutherland 1939, 1990, 1998) who created a model of a system of mutual tensions arising in the system skull-dura mater-sacral bone, called the craniosacral system (Sills 2001). It was observed that the cerebrospinal fluid flowing along the dura mater has its own rhythm and independent movement which continues throughout life (Upledger 1996, 1997; Sutherland 1998; Becker 2000; Sills 2001; Nelson et al. 2006; Kern 2010). In 1970, while assisting in a spine surgery, John Upledger, D.O. noticed that membranes surrounding the spinal cord continuously moved rhythmically under his fingers. It was this experience that made

Address for correspondence:

Weronika Kanik

Institute of Veterinary Sciences, Department of Veterinary, Reproduction and Welfare

of Animals, Faculty of Animal Breeding and Biology,

University of Agriculture in Krakow

Al. Mickiewicza 24/28, 30-059 Krakow, Poland

Phone: +48 793620932

E-mail: weronika.kanik@gmail.com

http://actavet.vfu.cz/ 
Upledger interested in studying the primary breathing rhythm of tissues, cells and fluids in the organism (Upledger 1991).

Positive effects of this therapy have been observed in cases of migraine, pains, sleeping disorders, anxiety and fear (Matarán-Peñarrocha et al. 2011; Arnadottir and Sigurdardottir 2013), fibromyalgia (Castro-Sánchez et al. 2011; MataránPeñarrocha et al. 2011), multiple sclerosis (Raviv 2009), asthma in children (Gillespie 2008) and in adults (Mehl-Madrona et al. 2007) as well as in a variety of neurological disorders that affect the central nervous system, in which CST stimulates general neuromuscular balance and improves the equilibration of muscular tension (Upledger and Vredevoogd 1983; Oschman 2000). Moreover, CST is effective as a supporting therapeutic method for children with developmental disorders, such as autism (Upledger and Vredevoogd 1983; Axt 1998) and it supports correct development of children and infants (Peirsmann 2011). Craniosacral therapy is also a method supporting rehabilitation and convalescence of animals, however, no available literature has been found except articles published on the Internet by M. Rogers, who has developed CST for horses, known as Equine Craniosacral Therapy (Rogers 2008, 2010).

At the beginning of 2011, the National Health Service (NHS) in Poland decided to acknowledge CST by a procedure classified by the NHS International Classification of Diseases, in Poland known as the International Classification of Medical Procedures (ICD-9), no. 93.3824, as a recommended rehabilitation method (ICD-9 PL v. 5.16 www.nfz.gov.pl/new access: 18.04.2012).

In Poland the practitioners' code of ethics and their standards of work were developed by the Polish Polarity and Craniosacral Association.

As some animals suffer from similar complaints as humans, the aim of the present study was to present a possibility to adapt CST used in human medicine for therapy in horses.

\section{Materials and Methods}

Craniosacral therapy - adaptation of the method

Therapeutic holds for equine craniosacral therapy were developed by the first author on the basis of relevant holds used in the biodynamic craniosacral therapy for people. The first author's own practice of many years standing and acquaintance with equine anatomy provided the basis for offering CST in rehabilitation, supporting treatment and prophylactics in horses. All therapies were performed by the first author, who is a certified CST practitioner in accordance with craniosacral therapy methodology as described by Franklyn Sills (Sills 2001, 2004, 2011, 2013) and the 6-level course in biodynamic CST conducted by Polarity/Craniosacral Associates of Montreal and in Poland by the Polish Polarity and Craniosacral Association (www.polarity-craniosacral.pl).

All procedures and therapeutic systems were applied with due attention and care, and were adjusted to the horses' behavior and their individual needs. Crouching positions in the vicinity of lower parts of legs and embracing the croup could be used only when such need arose and when it was possible to perform them, and the horse willingly and calmly accepted the therapy. Selected holds are presented below.

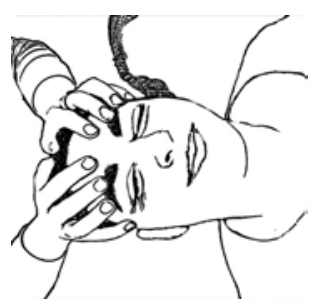

Fig. 1.1. Frontal hold in humans (adapted from Sills 2001)

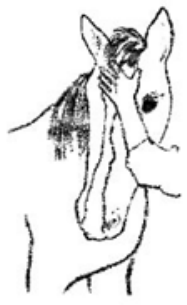

Fig. 1.2. Frontal hold in horses (drawing by W. Kanik)

\section{Frontal hold}

When the frontal hold is applied in humans, palms lie gently on the patient's forehead, with fingertips on the supraorbital ridge of the frontal bone, the tip of the ring finger lies on the connection of the frontal bone with the zygomatic bone, thumbs are crossed, but do not touch the head of the patient (Fig. 1.1) .

On a horse, this hold can be performed with one hand, as it is impossible to arrange hands in a similar way as on a human patient. The palm rests horizontally, slightly above the level of the eyes, covering the frontal suture, the tip of the thumb gently touching one part of the frontal bone and the tips of other fingers having contact with the other part, allowing for a free movement of the frontal bone (Fig. 1.2.). 


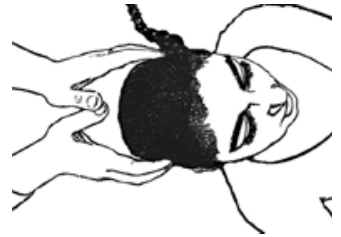

Fig. 2.1. Parietal hold in humans (adapted from Sills 2001)

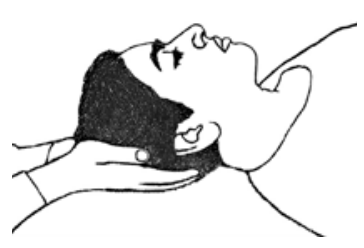

Fig. 3.1. Occipital cradle hold in humans (adapted from Sills 2001)

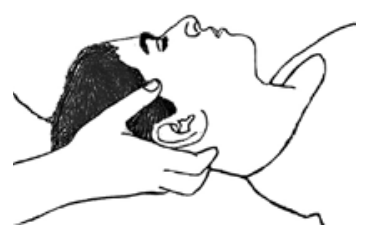

Fig. 4.1. Dr Becker's hold in humans (adapted from Sills 2001)

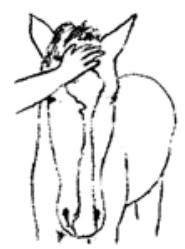

Fig. 2.2. Parietal hold in horses (drawing by W. Kanik)

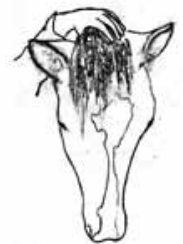

Fig. 3.2. Occipital cradle hold i horses (drawing by W. Kanik)

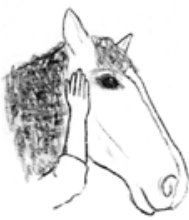

Fig. 4.2. Dr Becker's hold in horses (drawing by W. Kanik)

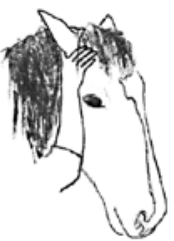

Fig. 5.2. Temporal bone hold in horses (drawing by W. Kanik)
Parietal hold

When the parietal hold is applied in humans, both hands embrace parietal bones, fingertips are placed above the squamous suture, thumbs crossed over the sagittal suture, not touching the head. (Fig. 2.1.)

On a horse this hold can be applied with one hand from the front or from the occipital side. Then the palm rests freely between the horse's ears along the sagittal suture on parietal bones and the interparietal bone. The tip of the thumb has contact with one parietal bone, the tips of other fingers with the other parietal bone. Simultaneously all fingertips receive information from the interparietal bone. (Fig. 2.2.)

\section{Occipital cradle hold}

In humans, the occipital cradle hold consists in putting hands under the head of the patient, fingertips cradling the occiput without applying pressure, thumbs lying freely. (Fig. 3.1.)

On a horse, it is possible to apply the occipital cradle hold with one hand resting between the ears, on the crest, slightly further caudally than in the parietal hold. The tip of the middle finger rests on the connection of the occipital bone with the interparietal bone (on the outer sagittal crest) the tips of the thumb and the little finger reach the connection of the occipital bone with the petrous part of the temporal bones on both sides. (Fig. 3.2.)

\section{Dr Becker's hold (for the sphenoid bone)}

In humans, palms cradle the head from the bottom, just like in the occipital cradle hold but they are directed slightly more outwards. Fingertips cradle the occipital and temporal bones, thumbs rest on the temples at the level of the greater wing of the sphenoid bone. (Fig. 4.1.)

In horses this hold can be applied by placing the tips of thumbs on the frontozygomatic and temporozygomatic sutures at the level of the pterygoid processes of the basisphenoid, and the other fingertips along the zygomatic processes of the temporal bones so that they can reach the basio-occipital bone which is located deeper inside the skull under the temporal bones. (Fig. 4.2.)

\section{Temporal bone hold}

When applying the temporal bone hold in humans the middle fingers are inserted gently in the ear in the external auditory matus, the ring fingers are placed below the ear on the mastoid portions, the index fingers on zygomatic processes of the temporal bones, little fingers on the occipital squama, and thumbs lie freely in a comfortable position. (Fig. 5.1.)

In horses, the temporal bone hold can be applied by embracing the horse's head from the bottom and the ears in such a way that the thumbs touch the

Fig. 5.1. Temporal bone hold in humans (adapted from Sills 2001) base of the ear caudally (the mastoid portions of the temporal bone) and the remaining fingers rest freely on the temples along the temporal crest or temporal line. If possible, fingers can also touch the zygomatic processes of the temporal bones (Fig. 5.2). 


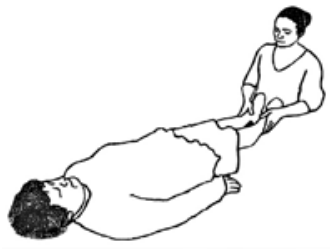

Fig. 6.1. Leg hold in humans (adapted from Sills 2001)

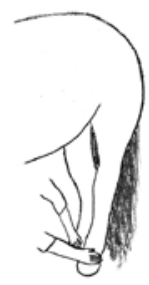

Fig. 6.2. Leg hold in horses (drawing by W. Kanik)

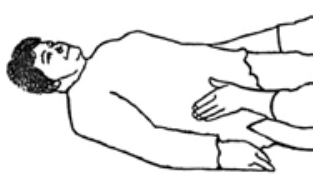

Fig. 7.1. Hold for innominate bones in humans (adapted from Sills 2004)

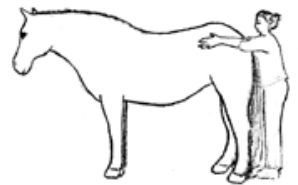

Fig. 7.2. Hold for innominate bone in horses (drawing by W. Kanik)

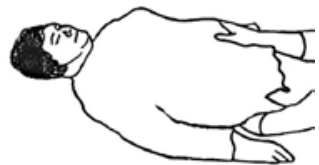

Fig. 8.1. Sacro-pelvic hold in humans (adapted from Sills 2004)

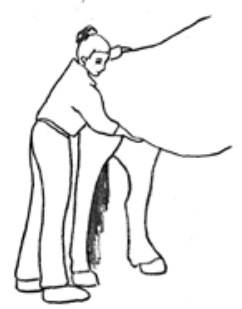

Fig. 8.2. Sacro-pelvic hold in horses (drawing by W. Kanik)

\section{Leg hold}

There are three versions of this hold in humans - gently holding the ankle joints from above (Fig. 6.1); gently holding the toes; a hold with palms placed under the heels and Achilles tendons of the patient.

In horses also several versions of this hold are possible - near the coronets (Fig. 6.2) and/ or near the fetlock joints and/or near the hocks. Depending on circumstances, this hold can be applied simultaneously on both legs or first on one leg, then on the other one. In the latter case it is advisable to finish by touching both legs in order to check the symmetry and quality of fluctuation of the cerebrospinal fluid and the balance of tension in the connective tissue of the organism.

Hold for the pelvic diaphragm, pelvic girdle and innominate bones

In humans in supine position, this hold is applied by placing hands freely on the anterior superior iliac spine (Fig. 7.1).

In horses in an upright position, hands embrace the croup from the back so that the palms can be placed freely on the points of hips; whereas in recumbency, depending on circumstances, also in such a way that palms can be placed on the points of hips.

For safety reasons, this hold can be administered only to horses familiar to the practitioner, taking appropriate security measures, such as maintaining the smallest possible distance between the practitioner and the croup of the horse (Fig. 7.2).

Sacro-pelvic hold for the pelvic diaphragm

In humans in supine position, the sacro-pelvic hold is applied by placing one hand under the sacral bone of the patient and the other hand on the lower abdomen between the anterior superior iliac spines, over the pubic symphysis (Fig. 8.1).

In horses in an upright position, the most convenient way of applying this hold is to place one hand at the level of the base of the sacrum, and the other one under the abdomen, in the pubic region (Fig. 8.2).

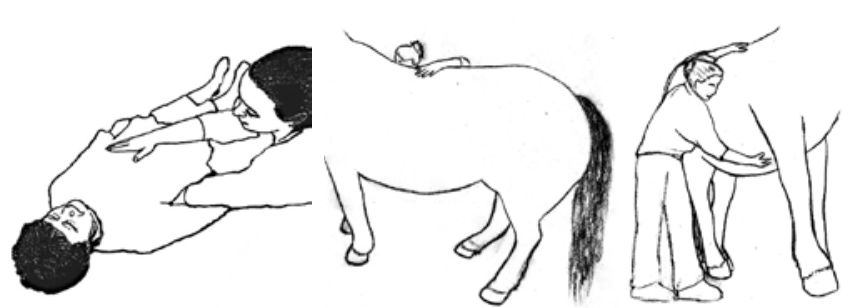

Fig. 9.1. Respiratory diaphragm hold in humans (adapted from Sills 2004)
Figs 9.2., 9.3. Respiratory diaphragm hold in horses (drawing by W. Kanik)
Respiratory diaphragm hold In humans in supine position, one hand is placed under the patient's back at the level of Th10L1 vertebrae, while the other hand on the area between the sternum, the xiphoid processes, and the solar plexus area (Fig. 9.1).

In a horse in an upright position, this hold can be applied by placing one hand at the level of vertebrae Th18(19)-L1, (Fig. 9.2) and the other hand ventrally at the level of the sixth rib, slightly below cartilago xiphoidea (Fig. 9.3). 


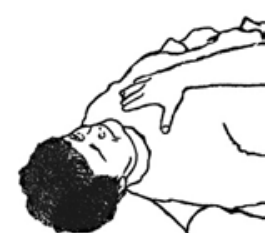

Fig. 10.1. Thoracic inlet hold in humans (adapted from Sills 2004)

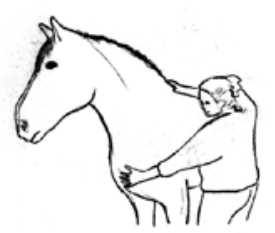

Fig. 10.2. Thoracic inlet hold in horses (drawing by W. Kanik)

\section{Thoracic inlet hold}

In humans in supine position, this hold is applied by placing one hand under the patient's body at the level of C7-T3 vertebrae, the other hand between the clavicles and the upper sternum, to make a sandwich (Fig. 10.1).

When applying this hold on a horse in upright position, one palm can be placed at the level of C7T2 vertebrae, and the other one between the greater tubercles of the horse's humerus, at the level of the manubrium of the sternum (horses do not have clavicles) (Fig. 10.2).

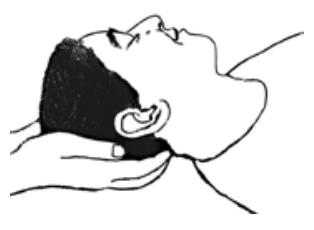

Fig. 11,1. Occipito-atlantal hold in humans (adapted from Sills 2004)

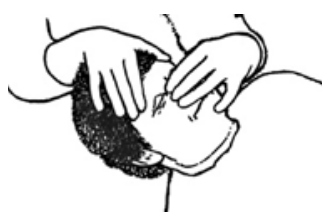

Fig. 12,1, Frontal-nasal hold in humans (adapted from Sills 2004)

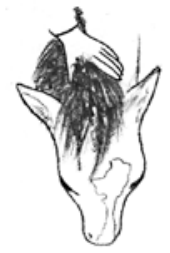

Fig. 11.2. Occipito-atlantal hold in horses (drawing by W. Kanik)

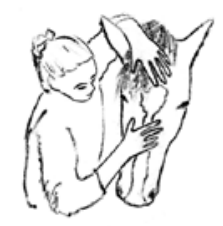

Fig. 12.2. Frontal-nasal hold in horses (drawing by W. Kanik)

\section{Occipito-atlantal hold}

In humans in supine position, in this hold fingertips are curled gently under the occipital squama, with thumbs lying freely (Fig. 11.1).

In horses, the most convenient way of applying this hold is to place the thumb and the index finger on the occipital crest or at the level of the occipital condyles. The other fingers are held freely, in the most comfortable position (Fig. 11.2).

\section{Frontal-nasal hold}

In humans in supine position, in this hold one palm very gently embraces the frontal bone, so that the tips of the thumb and the index finger or the ring finger touch the frontozygomatic suture. The tips of the thumb and the index finger of the other hand gently cradle nasal bones close to their joint with the frontal bone (Fig. 12.1).

On a horse, this hold can be applied by touching the occiput or the frontal bone with one palm and delicately embracing the nasal bones in the proximity of the frontonasal suture with the thumb and the index finger of the other hand (Fig. 12.2).

\section{Sacral and occipital hold}

In humans lying on their side, this hold is applied by placing one palm along the sacral bone and the other hand behind the patient's head, cradling the occiput (Fig. 13.1).

In most horses, due to significantly larger dimensions of their bodies, it is not possible to apply this hold in a similar manner. However, it can be done in two stages, first placing one palm on the connection of the sacral bone with the coccygeal part of the spine, and the other one on the withers (Fig. 13.2). Then the first hand is placed on the withers and the other one on the occiput (Fig. 13.3). The method of applying this hold and its stages can be modified to suit current needs. 
Thermographic measurements

Flir System thermographic camera, model Thermovision A20, with automatic ambient temperature compensation and thermographic camera Flir i7 Manual were used to measure the distribution of temperature on the surface of the horses' bodies. Obtained thermographs registered changes in the distribution of temperature in the affected areas before, during and on completion of the CST treatment. Measurements were performed in alignment with accepted methodology of thermographic research, inside a closed stable, with the animals placed at a distance of $1.5-2 \mathrm{~m}$ from the walls and partitions, in windless conditions.

Experimental material

The experimental material comprised horses undergoing therapy over three years (2010-2013). A total of 62 horses were studied ( 38 mares, 23 geldings, and 1 stallion) of different breeds, various ages, used in different ways, and suffering from different types of complaints. Craniosacral therapy was used to treat both horses with complex medical condition and horses with a single or one dominant problem. A full list of conditions treated with CST is presented in Tables $1-5$.

Horses were subjected to therapy in an atmosphere of comfort and freedom, as forcing the animal to undergo therapy when it is unwilling to receive it and to cooperate does not bring the desired effects and it can even be dangerous for the practitioner. Therapy was usually performed in the horse's box (occasionally outside the stable) in the presence of the owner or carer. All horses undergoing therapy were under regular veterinary supervision.

\section{Case taking}

For each therapy administration, including therapies aimed at changing the mental/emotional state of the animal, detailed records were kept, comprising the case history as reported by the owner/carer of the given horse (problem characteristics, general state of health before therapy, between therapies, and towards the end of the period covered by the present research), opinion and diagnosis of a veterinary surgeon, history of therapy and its effectiveness.

\section{Results}

The study analyzes therapy applied to 62 horses that were subjected to a total of 241 procedures of CST treatment. Depending on the effects of the therapy, the conditions occurring in the treated horses were measured on a four-grade scale (from 0 to 3 ) and collated in 5 groups (Tables 1-5). Depending on the individual case, the number of treatments for one horse varied from 1 to 21 and the mean duration of a single treatment was 45 min (from several minutes to over 2 hours).

Table 1. List of conditions in which therapy resulted in complete healing ( $3^{\circ}$ efficacy).

\begin{tabular}{rlrr}
\hline No. & \multicolumn{1}{c}{ Condition } & No. of cases & No. of treatments \\
\hline 1 & Dislodged vertebra, asymmetrical muscular tension & 4 & $1-6$ \\
2 & Intestinal colic & 2 & $1-3$ \\
3 & Renal colic & 2 & $1-2$ \\
4 & 3 degree lameness (sprained hock, excessive swelling, possible Achilles tendon rupture) & 1 & 15 \\
5 & Post-vaccination inflammation and swelling & 1 & 1 \\
6 & Diarrhoea and intestinal problems & 1 & 2 \\
7 & Aggravated allergic symptoms, discharge from the eyes & 1 & 2 \\
8 & Symptoms resembling equine rhabdomyolysis syndrome & 1 & 1 \\
9 & Adhesion on neck after an old injury, causing stiffness of muscles & 1 & 1 \\
10 & Distorted pelvis, dislocated sacrum & 1 & 6 \\
11 & Swollen cannons & 1 & 2 \\
\hline
\end{tabular}


Table 2. List of conditions in which therapy resulted in considerable improvement ( $2^{\circ}$ efficacy).

\begin{tabular}{clcc}
\hline No. & \multicolumn{1}{c}{ Condition } & No. of cases & No. of treatments \\
\hline 1 & Intestinal problems (suspected susceptibility to ulcers) & 2 & $1-2$ \\
2 & Large swelling and discharge of unknown origin in knee area & 1 & 2 \\
3 & Croup muscle defect and resulting impairment of muscular tension & 1 & 4 \\
4 & Buck knee & 1 & 5 \\
5 & Tendinitis, swelling & 1 & 4 \\
6 & Unpredictable behaviour, aggression towards humans & 1 & 4 \\
\hline
\end{tabular}

Table 3. List of conditions in which therapy resulted in partial improvement $\left(1^{\circ}\right.$ efficacy).

\begin{tabular}{llcc}
\hline No. & \multicolumn{1}{c}{ Condition } & No. of cases & No. of treatments \\
\hline 1 & Post-operative swelling of the stifle area, sore back & 1 & 2 \\
2 & Diarrhoea, diminished appetite (narrowed section of intestine) & 1 & 8 \\
3 & COPD, difficulty breathing & 1 & 2 \\
4 & Coon foot & 1 & 21 \\
5 & Extensive phlegmon of one leg & 1 & 11 \\
6 & Equine viral arteritis & 1 & 12 \\
7 & Recurrence of tendon contracture & 1 & 12 \\
8 & Acquired heart defect (mitral regurgitation), excessive sweating & 1 & 6 \\
9 & Foreleg founder, excessive weight & 1 & 4 \\
\hline
\end{tabular}

Table 4. List of conditions in which the efficacy of therapy was different in different individuals ( $0-3^{\circ}$ efficacy).

\begin{tabular}{|c|c|c|c|c|c|c|c|}
\hline \multirow[t]{2}{*}{ No. } & \multirow[t]{2}{*}{ Condition } & \multicolumn{5}{|c|}{$\begin{array}{c}\text { No. of cases } \\
\text { with given level } \\
\text { of improvement }\end{array}$} & \multirow[t]{2}{*}{$\begin{array}{l}\text { No. of } \\
\text { treatments }\end{array}$} \\
\hline & & $\overline{\sum^{*}}$ & 0 & 1 & 2 & 3 & \\
\hline$\overline{1}$ & Motor disorders & 12 & 1 & 4 & 5 & 2 & $2-21$ \\
\hline 2 & Splints & 4 & & 1 & 2 & 1 & $1-6$ \\
\hline 3 & Disorders of muscular tension & 11 & & 1 & 7 & 3 & $1-11$ \\
\hline 4 & $\begin{array}{l}\text { Disorders of muscular tension connected with well-developed } \\
\text { musculature }\end{array}$ & 5 & & 3 & 2 & & $1-2$ \\
\hline $5 \mathrm{a}$ & Lameness & 14 & 1 & 7 & 3 & 3 & $1-15$ \\
\hline $5 b$ & Lameness due to bruised sole & 4 & & 4 & & & $1-3$ \\
\hline 6 & Sore back, visible ribs, frequent apathy & 3 & 1 & & 1 & 1 & $1-5$ \\
\hline 7 & Strong stress connected with change of stable & 2 & & & 1 & 1 & 1 \\
\hline 8 & Considerable hyperactivity and spooking & 5 & & & 2 & 3 & $1-5$ \\
\hline 9 & Deformation of joints, including the spine & 4 & & 2 & 2 & & $1-21$ \\
\hline 10 & $\begin{array}{l}\text { Apathy, diminished fitness, aversion to humans } \\
\text { (due to age and past abuse) }\end{array}$ & 8 & 1 & 2 & 3 & 2 & $1-11$ \\
\hline 11 & Swollen legs & 3 & & & 2 & 1 & $2-5$ \\
\hline 12 & Stiffness and swelling of fetlock (past injury) & 2 & & 1 & & 1 & $3-5$ \\
\hline 13 & Circulation disorders & 6 & 1 & 1 & 1 & 3 & $2-12$ \\
\hline 14 & Soft lesion of unknown origin on lumbar vertebrae & 2 & & 1 & & 1 & $2-3$ \\
\hline
\end{tabular}

$* \sum$ - no. of

total cases in particular condition 
Table 5. List of conditions in which therapy did not result in improvement ( $0^{\circ}$ efficacy).

\begin{tabular}{llcc}
\hline No. & \multicolumn{1}{c}{ Condition } & No. of cases & No. of treatments \\
\hline 1 & Blindness or narrowing of the visual field & 3 & $1-2$ \\
2 & Minor fungal lesions & 1 & 3 \\
3 & Difficulty breathing, cough & 1 & 8 \\
4 & Lymphoblastoma of ethmoid bone, nosebleed & 1 & 2 \\
5 & Endocrine-inactive tumorous lesion on the thyroid gland & 1 & 2 \\
6 & Standing under (conformation fault) & 1 & 4 \\
7 & Palsy caused by a fracture of one of the cervical vertebrae & 1 & 2 \\
8 & Volvulus & 1 & 1 \\
9 & Problems in maintenance routines and work, "hard-mouthed" & 1 & 2 \\
\hline
\end{tabular}

\section{Discussion}

Available scientific sources do not comprise information on the possibility of applying craniosacral therapy in treating animals. Sparse information can be found on websites. Maureen Rogers $(2008,2010)$ is considered to be a pioneer in using craniosacral therapy in horses. It is acknowledged to be a non-invasive and effective method in treating numerous complaints in horses, such as lameness, head shaking syndrome, balance disorders, head injuries, facial palsy, problems with lower spine and joints (especially stifle and hock), in acute and chronic injuries as well as in problems of behavioural nature. This therapy is also recommended in cases of wind-sucking, bucking, problems with transitions in riding, breathing dysfunctions, after filing teeth and in case of problems with chewing the feed. Rogers $(2008,2010)$, refers to it as a unique and exceptionally effective method allowing to restore (or maintain) the health of horses in their natural biomechanical balance. Rogers (2010) also emphasises the significance of the craniosacral system and craniosacral therapy in removing limitations and dysfunctions in the whole musculoskeletal and nervous system and restoring the balance of posture, fluidity of movement, removing pain and discomfort, and improving the wellbeing of the animal, which has an impact on its willingness to co-operate with people.

According to Sills (2001, 2004, 2011, 2013), Upledger (Upledger and Vredevoogd 1983, Upledger 1997) and Cohen (1995), in humans such limitations may be caused by impaired fluctuation of the cerebrospinal fluid which takes the form of transverse fluctuation or inertial fulcrums, or else energetic cysts appearing in any part of the organism. Upledger (2002) defines energetic cysts as energy accumulated in one point in the connective tissue as a result of different injuries (both mental and physical), accumulation of toxins, activity of microorganisms and/or irradiation. Energetic cysts usually block or even make impossible the process of healing, often cause physical pain and even limit the motility of joints. Energetic cysts are not detectable by ultrasound imaging or x-ray, however they can be detected by palpation and sometimes are visible in the form of a swelling or callus.

In most cases, the specificity and location of lesions (inside the body with no outward appearance, e.g., navicular problems, stiffness in joints or tendons apparent only in movement) and processes occurring in the organism during therapy (recovery from colic, improved motility of intestines) are difficult and sometimes impossible to depict and present. These processes are often accompanied by unblocking an energetic cyst, releasing energy accumulated in it and restoring homeostasis in the organism (Upledger 2002). In the light of the above information, a thermographic camera was suggested as a means of registering processes taking place during therapy. The camera was used to record changes in the distribution of temperature on the surface of the body during the administration 
of craniosacral therapy. The thermogram below depicts the process of unwinding an energetic cyst in the right hock of a horse during treatment that had been invisible until then (Plate II, Figs 14-17).

A thermographic camera was also used to document the effects of CST in the fetlock and the fetlock joint area of a horse whose fluidity of movement was visibly hampered due to an unknown cause. Thermograms suggest impaired circulation in the left limb (Plate III, Fig. 18). After topical therapy, fluidity of movement improved, adequate circulation and temperature of body in this area were restored, and the surface skin temperature on both front limbs became equal (Plate III, Fig. 19). Comparing the thermograms recorded before and after the therapy, one can infer that the right front leg had been overloaded before the therapy (probably as a result of compensation). In the analysed case, the therapy brought lasting effects, as demonstrated not only by the way the horse moved, but also by similar distribution of temperature on the limbs shown in the control thermograms taken in the summer, 12 weeks after commencing therapy (Plate III, Fig. 20).

The craniosacral therapy practitioner does not diagnose the cause of an illness and focuses on helping the patient, treating each case individually. In craniosacral therapy, the main aim is to balance the fluctuation of the cerebrospinal fluid and to regulate the flow of energy in the organism. In horses, just like in people, this therapy is of a complex character. Topical treatment affects the whole organism and it is often difficult to distinguish the cause and the result. The feel of the practitioner is important in each treatment. Illnesses may have different backgrounds, being also caused by injury, inflammation or mental trauma.

On the basis of the first author's observation and many years of practice in treating people and horses, it was observed that numerous similarities in reactions occur during and after the treatment of human and equine patients. During the treatment of both, the same therapeutic processes take place, e.g. fluctuations, unwinding, silencing, pulsing, heating of tense muscles, etc. The response of horses and people to applied therapy is also similar and manifests itself as relaxation, sighing, sleepiness, yawning, holding breath or deeper breathing and regulation of intestinal motility. Additionally in horses, other manifestations are observed, such as the lowering of the head and neck, closing eyes, lowering the chin, in males the exserting of the penis, and even lying down and falling asleep.

A fundamental difference between the therapy of horses and the therapy of people is that it is difficult to "persuade" an animal to undergo the treatment if it is not willing to, which is why the duration of particular treatments can vary. Moreover, in animals it is not always possible to apply all holds prescribed by the assumed therapy protocol and sometimes the situation demands using more holds. It is a very individual and varied issue. Similarly, the illnesses and complaints of horses vary considerably. There are no two identical cases or two identical therapies. The reaction of the organism, duration and number of treatments necessary to achieve a positive result in a given health problem are also very individual. The reason for starting craniosacral therapies in horses was mainly the desire and need to help the affected animal in situations when traditional and conventional methods proved insufficient and the health problem was recognized as a hopeless one, and the therapy was applied to support conventional methods of treatment and convalescence. All horses undergoing craniosacral therapy were under regular veterinary supervision.

As the results of own research imply, CST proves to be a highly effective method of supporting treatment of horses in cases of significant impairment of circulation, muscular tension disorders, dislocation of vertebrae, intestinal and renal colic, inflammation, swelling and many others listed in Table 1 . In view of achieved results, the therapy can also be recommended in several conditions in which it resulted in partial or significant improvement in health (Tables 2-4). However, in certain other conditions, the therapy did not result in improvement (Table 5).

The effects of own practice and data available in literature suggest that craniosacral 
therapy seems to be an effective method of improving the state of health of horses suffering from different complaints which can cause significant difficulty in sport, breeding or private use of the animals. Using a thermographic camera for the research enabled the researchers to register some processes taking place during the therapy, which had been impossible until then.

\section{Conflict of interest}

The authors declare that there are no conflicts of interest.

\section{Acknowledgement}

This paper was supported by DS-3263/ZWRiDZ. The authors wish to thank Łukasz Ziembla for the help in the graphic design of figures presenting holds for humans.

\section{References}

Arnadottir TS, Sigurdardottir AK 2013: Is craniosacral therapy effective for migraine? Tested with HIT-6 Questionnaire. Complementary Therapies in Clinical Practice 19: 11-14

Axt A 1998: Autism viewed as a consequence of pineal gland malfunction. Farmakoter Psychiat Neurol 1: 112134

Becker R 2000: The Stillness of Life. Stillness Press.

Castro-Sánchez AM, Matarán-Peñarrocha GA, Sánchez-Labraca N, Quesada-Rubio JM, Granero-Molina J, Moreno-Lorenzo C 2011: A randomized controlled trial investigating the effects of craniosacral therapy on pain and heart rate variability in fibromyalgia patients. Clin Rehabil 25: 25-35

Cohen D 1995: An Introduction to Craniosacral Therapy. Anatomy, Function and Treatment. Berkeley: North Atlantic Books

Gillespie BR 2008: Case study in pediatric asthma: The corrective aspect of craniosacral fascial therapy. ExploreNY 4: 48-51

Kern M 2005: Wisdom in the Body: The Craniosacral Approach to Essential Health. USA, North Atlantic Books

Matarán-Peñarrocha GA, Castro-Sánchez AM, Carballo García G, Moreno-Lorenzo C, Carreño TP, Zafra M 2011: Influence of Craniosacral Therapy on Anxiety, Depression and Quality of Life in Patients with Fibromyalgia. Evidence Based Complementary and Alternative Medicine, Article ID 178769

Mehl-Madrona L, Kligler B, Silverman S 2007: The impact of acupuncture and craniosacral therapy interventions on adults with asthma. Explore-NY 3: 28-36

Nelson KE, Sergueef N, Glonek T 2006: Recording the rate of the Cranial Rhythmic Impulse. J Am Osteopath Assoc 6: 337-341

Oschman J 2000. Energy Medicine: The Scientific Basis. Churchill Livingstone

Peirsmann N, Peirsmann E 2011: Terapia czaszkowo-krzyżowa u dzieci i niemowląt. Warszawa, Virgo. (original title: Craniosacral Therapy for Babies and Small Children)

Raviv G, Shefi S, Nizani D, Achiron A 2009: Effect of craniosacral therapy on lower urinary tract signs and symptoms in multiple sclerosis. Complementary Therapies in Clinical Practice 15: 72-75

Rogers M 2008: Craniosacral Aspect of Head Trauma. Australia's Hoofbeats Magazine August/September: 31-32

Rogers M 2010. Equine CranioSacral Therapy: Keep the Equine Body in Balance with a Light Touch. Natural Horse Magazine January/February: 24-27

Sills F 2001: Craniosacral Biodynamics vol. 1. Berkeley, California: North Atlantic Books.

Sills F 2004: Craniosacral Biodynamics vol. 2. Berkeley, California: North Atlantic Books.

Sills F 2011: Foundations in Craniosacral Biodynamics vol. 1. Berkeley, California: North Atlantic Books.

Sills F 2013: Foundations in Craniosacral Biodynamics vol. 2. Berkeley, California: North Atlantic Books.

Sutherland WG 1939: The cranial bowl. Mankato, Minnesota: Free Press; reprinted 1986.

Sutherland WG 1998: Contributions of Thought: The Collected Writings of William Garner Sutherland. Fort Worth, Texas: The Sutherland Cranial Teaching Foundation. (Edited by: Sutherland AS, Wales A)

Sutherland WG 1990: Teaching in the Science of Osteopathy. Portland, Oregon: Rudra Press. (Edited by: Wales A.L.)

Upledger JE, Vredevoogd J 1983: Craniosacral Therapy. Seattle: Eastland Press.

Upledger JE 1991: Your Inner Physician and You. Berkeley, CA: North Atlantic Books.

Upledger JE 1996: The Brain Is Born. Berkeley, California: North Atlantic Books.

Upledger JE 1997: Your Inner Physician and You: CranioSacral Therapy and SomatoEmotional release. Seattle, DC, USA: Publishers Group West.

Upledger JE 2002: SomatoEmotional Release: Deciphering the Language of Life. Berkeley, California: North Atlantic Books.

Whedon JM, Glassey D 2009: Cerebrospinal fluid stasis and its clinical significance. Altern Ther Health M 3 : 54-60 
Plate II

Kanik W. et al.: Adapting craniosacral ... pp. 75-84

Figs 14-17. Thermograms depicting the process of unwinding an energetic cyst during craniosacral therapy (thermograms by J. Augustyn; thermografic camera model Thermovision A20).



Fig 14. Before starting therapy - 19:17 h

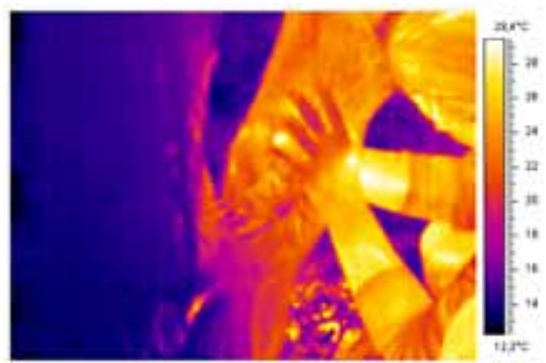

Fig 15 . Two min after starting therapy $-19: 19 \mathrm{~h}$

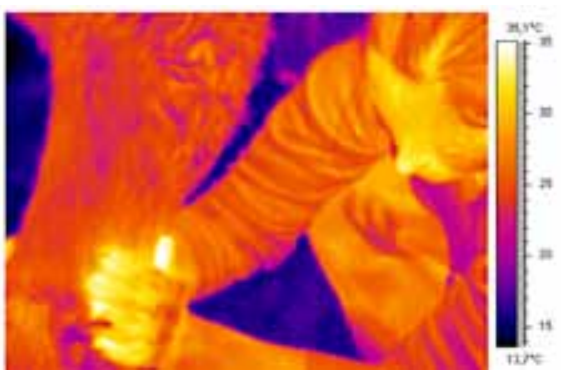

Fig 16. At 19:23 h

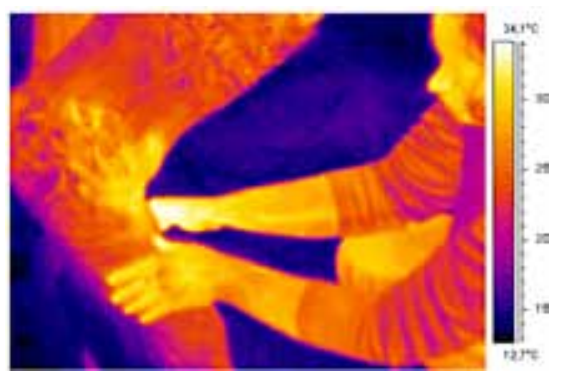

Fig 17. Eight min after starting therapy - 19:25 h 
Figs 18-20. Thermograms depicting the effects of craniosacral therapy in the fetlock and fetlock joint area of a horse whose fluidity of movement was visibly hampered due to an unknown cause (thermograms by W. Kanik; thermografic camera model Flir i7 Manual).

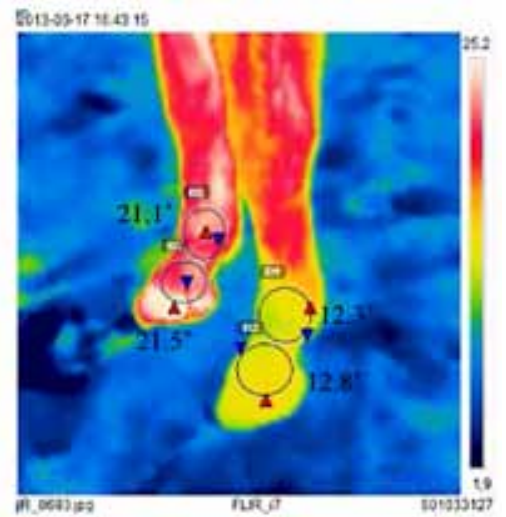

Fig 18. Thermogram recorded before therapy

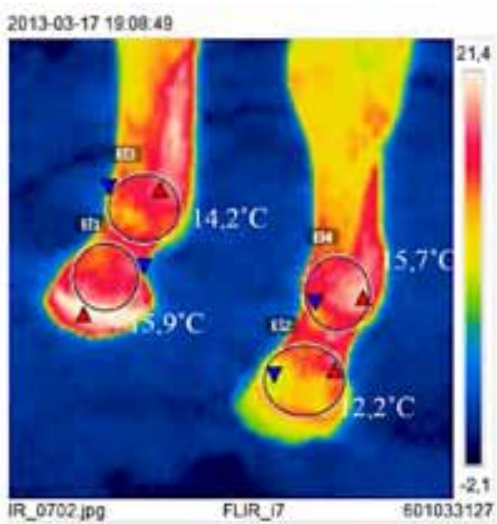

Fig 19. Thermogram recorded after therapy

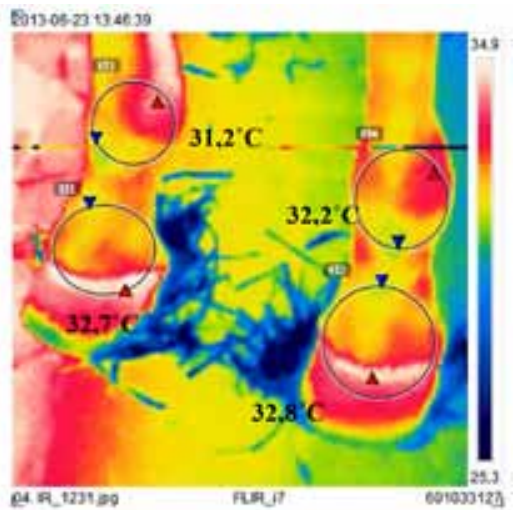

Fig 20. Control thermogram recorded 12 weeks after therapy 